\title{
Antibacterial activity of plant extract and zinc nanoparticles obtained from Syzigium aromaticum $\mathbf{L}$.
}

\author{
Sumera Javad*, Iqra Akhter, Khadija Aslam, Amina Tariq, Nadia \\ Ghaffar, Sumera Iqbal and Iqra Naseer \\ Department of Botany, Lahore College for Women University, Lahore-Pakistan \\ *Corresponding author's email: zif_4@yahoo.com \\ Citation \\ Sumera Javad, Iqra Akhter, Khadija Aslam, Amina Tariq, Nadia Ghaffar, Sumera Iqbal and Iqra Naseer. \\ Antibacterial activity of plant extract and zinc nanoparticles obtained from Syzigium aromaticum L. Pure and \\ Applied Biology. Vol. 6, Issue 4, pp1079-1087. http://dx.doi.org/10.19045/bspab.2017.600115
}

Received: 07/04/2017

Revised: $24 / 08 / 2017$

Accepted: 05/09/2017

Online First: 09/09/2017

\section{Abstract}

Nanotechnology deals with the use of nanoparticles in various remarkable fields of present time with vast medicinal, agricultural and industrial applications. Biological approaches using microorganisms and plants or plant extracts for metal nanoparticles, have been suggested as valuable alternatives to chemical methods. In present study Syzigium aromaticum L. extracts in water and ethanol were used for the green synthesis of zinc oxide nanoparticles. After being treated with zinc sulphate solution, the color of all the extracts of plant changed indicating the formation of zinc nanoparticles and their color change was also monitored by using Ultraviolet-Visible spectroscopy. Particle size analyzer showed $44.4 \mathrm{~nm}$ for water extract nanoparticles and 103nm for ethanolic NPs. Antibacterial activity of these nanoparticles was evaluated against four bacterial strains, namely Klebsiella pneumonia, Pseudomonas aureginosa, Escherichia coli and Acetobactor bauminii. The zinc oxide nanoparticles of $S$. aromaticum developed by ethanolic extract did not show the significant antibacterial activity against any bacterial strain. The zinc nanoparticles of $S$. aromaticum developed by water extract showed maximum inhibition zone against $K$. pneumonia as $1.43 \mathrm{~mm}, P$. aureginosa is $1.00 \mathrm{~mm}, E$. coli as $2.14 \mathrm{~mm}$ and against $A$. bauminii as $2.30 \mathrm{~mm}$ as compared to $1.15 \mathrm{~mm}, 1.86 \mathrm{~mm}, 1.76 \mathrm{~mm}$ and $1.53 \mathrm{~mm}$ respectively by plant extract.

Keywords: Antimicrobial activity; Green nanotechnology; Microwave assisted extraction (MAE); Plant extract; Ultraviolet-visible spectroscopy (UV-Vis); Zinc nanoparticles

\section{Introduction}

Nanotechnology is a field of science which deals with production, manipulation and use of materials ranging in nanometers. The word nano derived from the Greek noun "nano" meaning "dwarf". The particle size of nanoparticles (NP) in medicine ranges from 5-250nm [1]. Nanotechnology deals with the production of nanomaterials having nanosizes, with different but controlled shapes. It also deals with their chemical composition, and is also concerned with the human benefits involved [2-4]. Use of microorganisms, plant biomass or plant extracts for the production of nanoparticles, has gained much interest in recent years. As 
plant based methods are more environment friendly as compared to commonly used physical and chemical methods. Historically, plants occupy a very vital position in medicines. Since long times plant parts have been in use as crude extracts, decoctions or mixtures for treatment of different ailments. Plants have been reported to have a broad spectrum antimicrobial spectrum against pathogenic microbes [5-8]. Plants continue to serve as possible sources for new drugs and chemicals derived from various parts of plants [9].

Every year numerous antimicrobial compounds are being added in medications which are created normally by living things. An investigation of these most basic microbiological behaviors towards nanoparticles may discover new antibacterials, and may lead to new era of antibiotics. By utilizing green strategies in the amalgamation of zinc oxide nanoparticles, it can be a turning point for the microbiology as conventional techniques are costly and require the utilization of synthetic solvents as reducing agents which are dangerous to environment. Zinc oxide $(\mathrm{ZnO})$ nanoparticles have gotten extensive consideration because of their antimicrobial, UV blocking, high reactant and photochemical exercises [10]. It has been reported that $\mathrm{ZnO}$ nanoparticles have antibacterial and antifungal properties even at lower concentrations subsequently reasonable for thin coating applications [11]. Clove is a valued and important spice of the world. It is a member of family Myrtaceae. It is an unopened flower bud growing on a tree. Cloves (Syzygium aromaticum Linn.) are the aromatic dried flower buds. Clove possesses antioxidant, antifungal, antiviral, antimicrobial, antidiabetic, antiinflammatory, antithrombotic, anesthetic, pain relieve and insect repellent properties $[12,13]$.
This study is conducted in order to understand the synthesis of nanoparticles by different concentration of clove extract. These biosynthesized nanoparticles were then studied for their antibacterial activity. The main objectives of the study are to develop nanoparticles, using Syzygium aromaticum Linn. as raw material, to optimize the conditions required for maximum amount of nanoparticles with less solvent and time consumption. The nanoparticles were also characterized with different parameters i.e., UV-Vis spectroscopy, particle size analyzer and antibacterial activity.

\section{Materials and methods}

\section{Preparation of plant extract}

The plant material i.e., clove buds (Syzygium aromaticum Linn.) was purchased from the local market. Plant material (20g) was weighed accurately by using electric balance and was converted into fine powder form by using pestle-mortar. Water $(100 \mathrm{~mL})$ was added in beaker for each sample. Plant material was allowed to expose to microwaves at 1000 watts for 120-150 seconds to get the extract. Whatmann No.1 filter paper was used for filtration. After filtration the extract was separated into three volumes i.e., $10 \mathrm{~mL}, 20 \mathrm{~mL}$ and $30 \mathrm{~mL}$ separately. Similar method was continued with ethanol for making of ethanolic extract.

\section{Preparation of reagent}

Zinc sulphate $\left(\mathrm{ZnSO}_{4}\right)$ solution was prepared by dissolving $0.65 \mathrm{~g}$ in $100 \mathrm{~mL}$ of water to form the reagent that reacts with plant extract for the formation of nanoparticles. Then $10 \mathrm{~mL}$ of salt solution were added in each volume of plant extract. Synthesis of Zinc oxide nanoparticles was analyzed over a period of 4 hours. It was mainly done by visual aid and UV visible spectrophotometry. Pictures were taken every hour to make the record of color change [14]. 


\section{Centrifuge}

After 4 hours the portions of solutions were taken in eppendorfs to centrifuge at 10000 rpm for 5 minutes. The purpose is to separate the nanoparticles in the form of pallets and to separate it from the debris. After thorough washing and drying at $50^{\circ} \mathrm{C}$ for 4-5 hours, pellets were then stored in refrigerator as $\mathrm{ZnO}$ nanoparticles.

\section{UV-Spectrophotometry}

This technique was used as a tool to determine the formation of nanoparticles. Formation of nanoparticles was monitored at regular intervals by taking its absorption spectrum within the wavelength range of 200-700nm on dual beam UV-Visible spectrophotometer.

\section{Antibacterial activity}

Antibacterial activity of various concentrations of synthesized zinc oxide nanoparticles (experimental), plant extracts as well as solvents' (control) was determined by agar well diffusion method. The autoclaved Muller \& Hinton agar media was mixed well and poured into $100 \mathrm{~mm}$ petriplates (20-25 $\mathrm{mL} /$ plate) while still molten. The media was allowed to solidify and left over night in incubator to check contamination. Then these properly labeled petri plates containing $20 \mathrm{~mL}$ media were inoculated with different cultures of bacterial strains. Four different human pathogenic species i.e.; Klebsiella pneumonia, Pseudomonas aureginosa, Escherichia coli and Acetinobactor bauminii were tested against experimental and control samples. Three wells were made in each plate with the help of cork borer and labeled properly. Zinc nanoparticles $(15 \mu \mathrm{l}$ solution of $20 \mathrm{mg} / \mathrm{mL}$ solution) and pure plant extracts (namely aqueous and ethanol extracts $1.5 \mu \mathrm{l}$ of each) were added in wells. The antibacterial components present in the experimental and control solution were diffused into medium and interacted with the test organisms freshly inoculated in Petri plates. Then the plates were kept in incubator for 24-36 hrs. After that, zones of inhibition were studied, measured and tabulated [15].

\section{Statistics}

The data thus generated was analyzed through statistical computer software SPSS. Means were analyzed by using one way ANOVA. Significance of the results was found by applying TUKEYS test at 5\% level of significance.

\section{Results}

The experiment was set up to examine the effect of different concentration of clove extract on formation of nanoparticles when the solvent was water. In this experiment control is the standard clove extract, while $10 \mathrm{~mL}, 20 \mathrm{~mL}$ and $30 \mathrm{~mL}$ are three volumes of clove extract with $10 \mathrm{~mL}$ of zinc sulphate solution $(4 \mathrm{mM})$ each and designated as $K_{1}$, $\mathrm{K}_{2}$ and $\mathrm{K}_{3}$ respectively. These three volumes were observed for the color change to indicate nanoparticles formation. The experiment was setup for 4 hours, to allow zinc sulphate to react with plant extract to form nanoparticles and it resulted in color change from dark brown to blackish brown (Figure 1) in different concentrations of clove extract which indicated the formation of zinc nanoparticles. 
Javad et al.

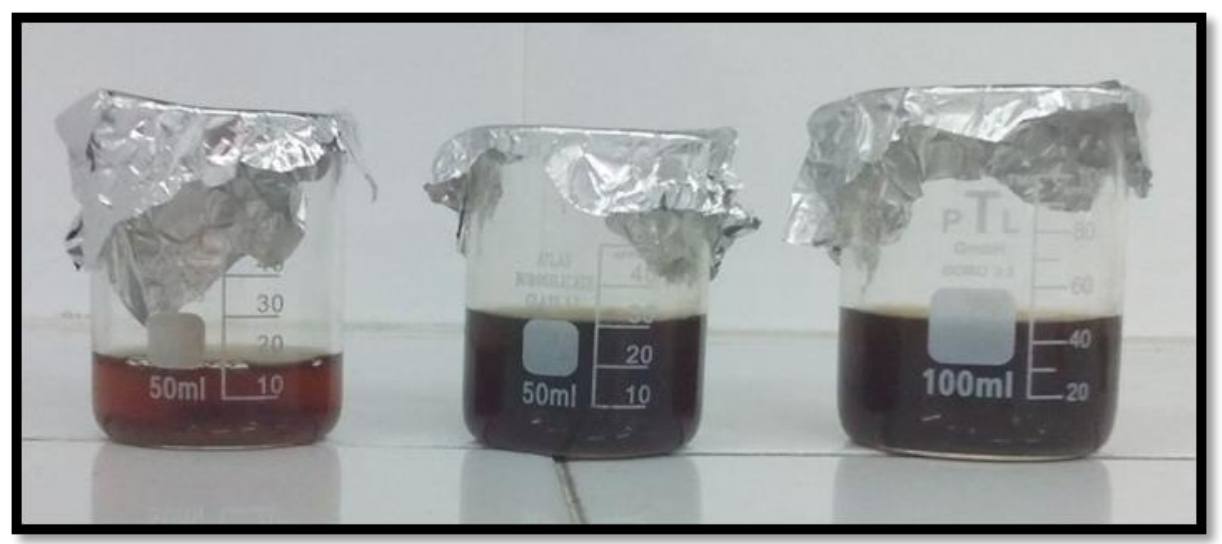

Figure 1. Color change in clove water extract with $\mathrm{ZnSO}_{4}$ solution

UV-Visible Spectrophotometery determines the formation of nanoparticles. UV-Vis absorption spectrum of clove plant extract and $\mathrm{Zn}$ nanoparticles samples are shown in Figure 2. UV-Visible spectrum of plant extract (clove) with water showed peak absorbance of 1.73 at wavelength of $230 \mathrm{~nm}$ whereas ZnNPs showed low peak absorbance than standard plant extract (clove) at wavelength $230 \mathrm{~nm}$ (with absorbance of 1.65 and 1.66 respectively). But ZnNPs of both volumes showed highest peak at wavelength $540 \mathrm{~nm}$ with absorbance of 2.0 and 1.92 respectively. This shows that the formation of $\mathrm{ZnNPs}$ in the reaction solutions (Figure 2). ZnNPs $30 \mathrm{~mL}\left(\mathrm{~K}_{3}\right)$ is almost as same as the standard plant extract and shows peak absorbance of 1.72 at wavelength of $230 \mathrm{~nm}$ due to very minute amount of formation of zinc nanoparticles which was also confirmed by very small pellet formed from this. Particle size analyzer (model BT-90 nano laser particle size analyzer) showed $44.4 \mathrm{~nm}$ size of $\mathrm{ZnO}$ NPs.

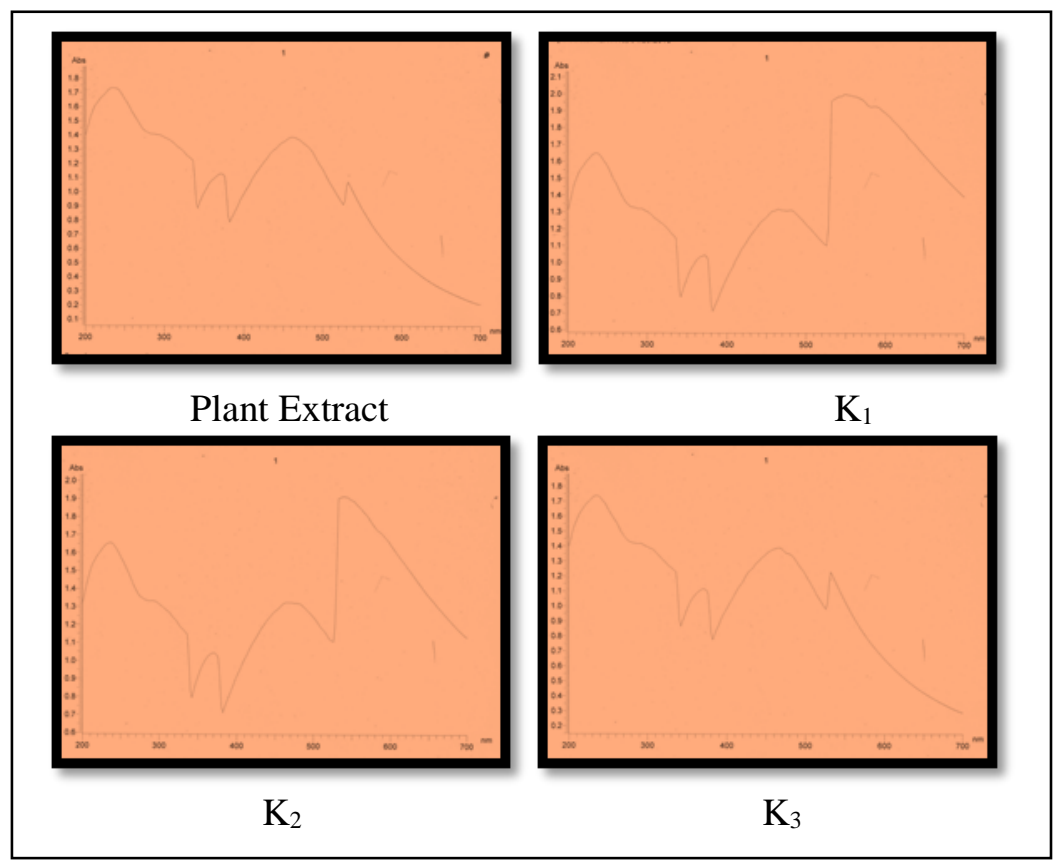

Figure 2. UV-Visible spectra of water plant extract, $\mathrm{ZnSO}_{4}+10 \mathrm{~mL}$ plant extract $\left(\mathrm{K}_{1}\right)$, $\mathrm{ZnSO}_{4}+20 \mathrm{~mL}$ plant extract $\left(\mathrm{K}_{2}\right), \mathrm{ZnSO}_{4}+30 \mathrm{~mL}$ plant extract $\left(\mathrm{K}_{2}\right)$ 
In the second experiment ethanol was used as a solvent instead of water and three volumes of reaction mixtures were labelled as $\mathrm{C}_{1}, \mathrm{C}_{2}$ and $\mathrm{C}_{3}$ respectively. The experiment was setup for 4 hours, to allow zinc sulphate to react with plant extract to form nanoparticles and it resulted in color change from pale yellow (Figure 3) to dark yellow and settlement of off-white mass at base in different concentrations of clove extract which indicated the formation of zinc oxide nanoparticles.

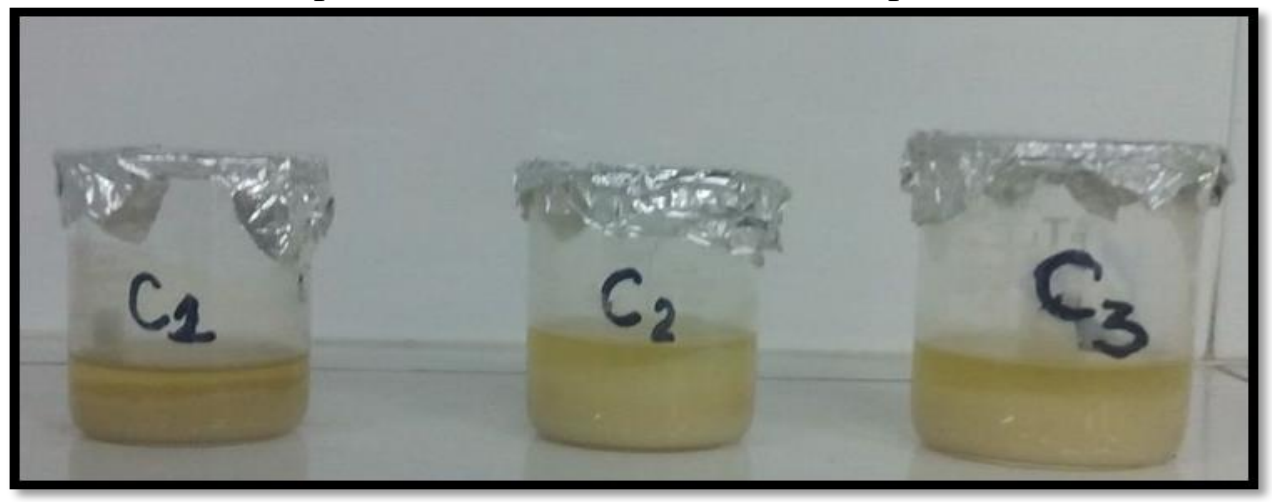

Figure 3. Color change in clove ethanol extract with $\mathrm{ZnSO}_{4}$ solution

UV-Visible Spectrophotometery is shown in Figure 4. Absorbance peak in UV-Visible spectrum showed by plant extract (clove) with ethanol is 1.40 at wavelength of $290 \mathrm{~nm}$ while at the same wavelength $(290 \mathrm{~nm})$ ZnNPs formed by $10 \mathrm{~mL}\left(\mathrm{C}_{1}\right), 20 \mathrm{~mL}\left(\mathrm{C}_{2}\right)$ and $30 \mathrm{~mL}\left(\mathrm{C}_{3}\right)$ volumes showed low peak absorbance than standard plant extract (clove). Absorbance of ZnNPs formed by 10
$\mathrm{mL}\left(\mathrm{C}_{1}\right), 20 \mathrm{~mL}\left(\mathrm{C}_{2}\right)$ and $30 \mathrm{~mL}\left(\mathrm{C}_{3}\right)$ volumes showed highest peak at wavelength $550 \mathrm{~nm}$ with absorbance value of 2.10 . It means all the concentrations of particles formed have same characteristics as their peaks absorbance values are same at same wavelength. While $\mathrm{Zn}$ nanoparticles formed were of size $103 \mathrm{~nm}$.

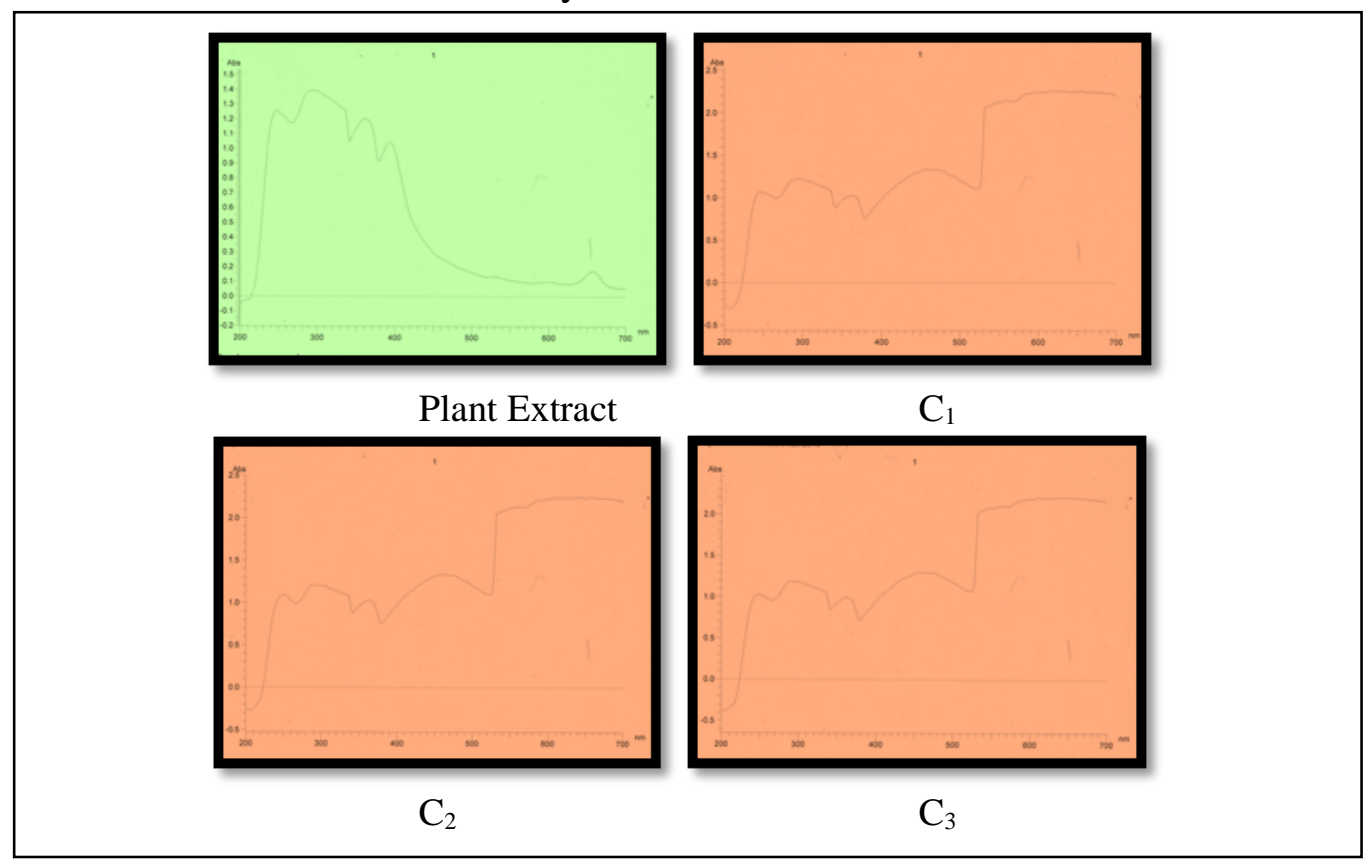

Figure 4. UV-Visible spectra of ethanolic plant extract, $\mathrm{ZnSO}_{4}+10 \mathrm{~mL}$ plant extract $\left(\mathrm{C}_{1}\right)$, $\mathrm{ZnSO}_{4}+20 \mathrm{~mL}$ plant extract $\left(\mathrm{C}_{2}\right), \mathrm{ZnSO}_{4}+30 \mathrm{~mL}$ plant extract $\left(\mathrm{C}_{2}\right)$ 
The plant extract composition of clove with zinc sulphate was tested to find their antibacterial ability against four different bacterial strains namely, $K$. pneumonia, $E$. coli, A. bauminii and $P$. aureginosa. The bacterial species were grown on petri dishes. The activity was observed as the bacterial streaks disappeared from the surrounding area of the wells called inhibition zone. These are the results of activity of nanoparticles against the bacterial species. These inhibition zones were to calculate approximately the antibacterial activity of nanoparticles and to make their comparison with that of plant extracts. Statistical analysis of these estimated inhibition zones provide the difference between clove plant extract antibacterial activity and its ZnNPs antibacterial activity. Figure 5 and 6 show the antibacterial activity of nanoparticles of water and ethanol against $K$. pneumonia (1.43mm and $1.066 \mathrm{~mm})$, E.coli $(2.14 \mathrm{~mm}$ and $1.78 \mathrm{~mm}), A$. bauminii $(2.3 \mathrm{~mm}$ and $1.83 \mathrm{~mm})$ and $P$. aureginosa $(1 \mathrm{~mm}$ and $1.73 \mathrm{~mm}$ ) respectively which were significantly different from the pure plant extract that were $1.15 \mathrm{~mm}, 1.766 \mathrm{~mm}$, $1.53 \mathrm{~mm}$ and $1.86 \mathrm{~mm}$ respectively. In $K$. pneumonia a higher antibacterial activity of water NPs was observed as compared to plant extracts and ethanolic nanoparticles formed. Pure plant extract showed lesser antimicrobial efficiency against $E$. coli as compared to nanoparticles. In A. bauminii nanoparticles shows more efficiency against antibacterial activity as compare to plant extract. In case of $P$. aureginosa pure plant extract showed more antimicrobial efficiency as compared to nanoparticles.

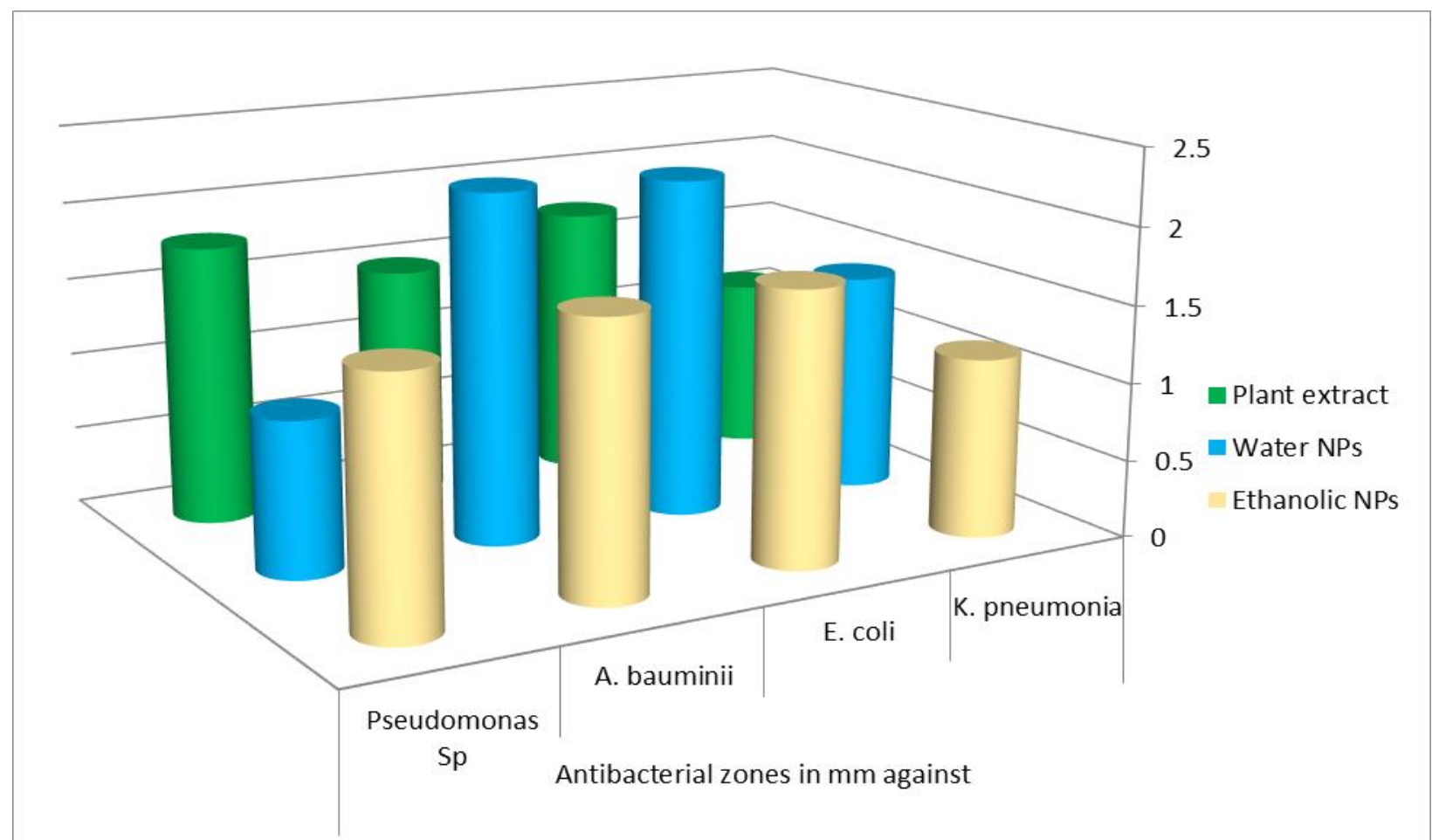

Figure 5. Antibacterial activity of plant extract of Syzigium cumini and nanoparticles formed by it 


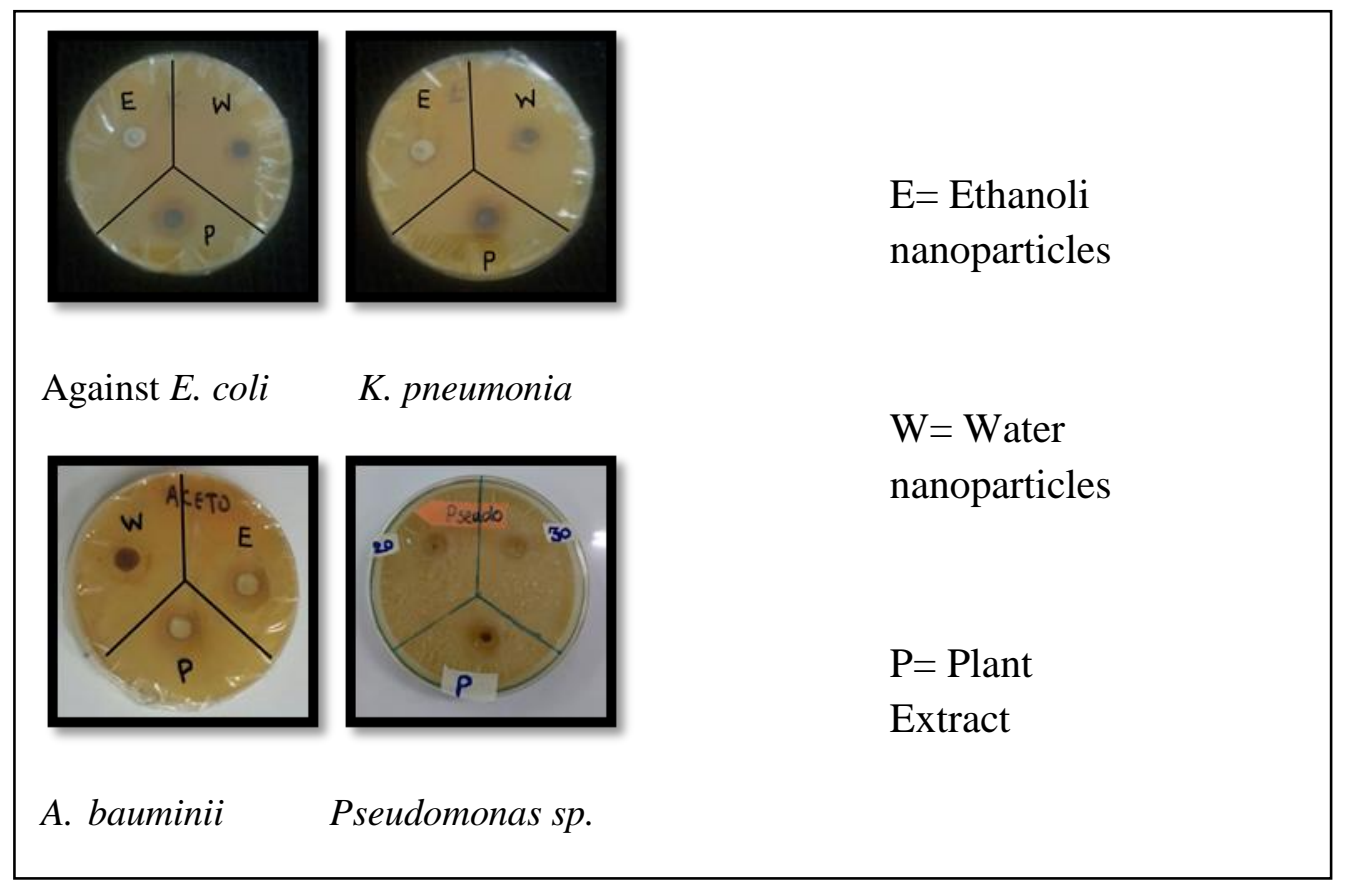

Figure 6. Antibacterial zones in $\mathbf{m m}$ against selected bacterial strains

\section{Discussion}

In the past few years, the use of nanoparticles has been dramatically increased in different applied fields of science and technology. Their uses are ranging from material science to biotechnology. Thus, the synthesis of nanoparticles can be considered as a dynamic area in research and application of nanoparticles. The different methods of nanoparticle synthesis include physical, chemical and biological methods. Of these methods, the biological synthesis is to be comparatively widely used due to its advantages of being low cost, non-toxic and environmental friendly. Bioapplications of nanoparticles have paved way for green synthesis of nanoparticles [16]. The plant used in the present study was clove (Syzygium aromaticum) to obtain extracts with different solvent i.e., water and ethanol. It was found that plant used formed nanoparticles as their extract color changed after reacting with zinc sulphate $\left(\mathrm{ZnSO}_{4}\right)$. The color change was from dark brown to blackish brown for water extract, while for ethanol extract it was a change of pale yellow to dark yellow. Color change was also monitored by changing maximum absorption wavelength with the help of UVVIS spectrophotometer. Ojha studied the synthesis of silver nanoparticles and their efficiency in clove. Their study concluded that clove nanoparticles formation was observed by the change in color. UV spectroscopy studies reported the maximum absorbance of silver nanoparticles reduced by Lavang extract at $417 \mathrm{~nm}$ [17]. Pattanayak demonstrated that Clove Bud extract is capable of producing iron nanoparticles that shows good stability in solution, under the UV-Visible wavelength nanoparticles shown quiet good surface Plasmon resonance behavior [18]. Shah stated that when the leaf extract incubated with $\mathrm{Zn}$ nitrate, the color changed from pale yellow to pale brown after one hour of incubation at room temperature. The change in color indicates the formation of nanoparticles. UV spectroscopy analysis showed maximum absorption at about 330 nm.Antibacterial activity test was performed 
to find out the extent and efficiency of the formed nanoparticles. For this purpose four different human pathogenic species were used namely Klebsiella pneumonia, Pseudomonas aureginosa, Escherichia coli and Acetinobactor bauminii. It was found that the largest inhibition zone against Klebsiella pneumonia, Escherichia coli and Acetinobactor bauminii was formed by the clove ZnNPs in aqueous solution, which was $1.43 \mathrm{~mm}, 2.14 \mathrm{~mm}$ and $2.30 \mathrm{~mm}$ respectively. Water ZnNPs have showed more efficiency in antibacterial activity than ethanol ZnNPs [19]. It has been reported earlier that the antibacterial efficiency of the nanoparticles is inversely related to their size [20]. $\mathrm{ZnO}$ nanoparticles increase the membrane permeability and then accumulate in bacterial cytoplasm and kill them. $\mathrm{ZnO}$ nanoparticles with plant metabolites may be more effective in this regard. Bacteria has proteins and other glycolipids on their surfaces and Plant metabolites stuck on the surface of nanoparticles interact with those membrane conjugates. So they cause death of bacterial cells more effectively $[21,22]$.

\section{Conclusion}

The present study deal with the biosynthesis of zinc oxide nanoparticles using the plant extracts of clove (Syzygium aromaticum). Clove can be a good source for the synthesis of zinc oxide nanoparticles. Particles are highly stable and showed high solubility in water. The synthesized $\mathrm{ZnO}$ nanoparticles were checked for antibacterial activity which may be due to the reactive oxygen species produced by the nanoparticle against bacteria as well as due to the electrostatic interaction between nanoparticles and bacterial species. Moreover the size of the nanoparticle also influenced the nanoparticle's antibacterial activity. The $\mathrm{ZnO}$ nanoparticle shows higher activity against gram negative bacterial strains than the gram positive strains.

\section{Authors' contributions}

Conceived and designed the experiments: S Javad, Performed the Experiments: N Ghaffar \& K Aslam, Analyzed the Data: A Tariq \& S Iqbal, Wrote the paper: I Akhtar \& I Naseer.

\section{Acknowledgments}

We Acknowledge Dr. Akhyar Farrukh, Nanochemistry Lab, Govt. College University Lahore, Pakistan for help in analyzing the size of nanoparticles.

\section{References}

1. Moghini SM, Hunter AC \& Murray JC (2005). Nanomedicine: current status and future prospects. FASEB Journal 19: 311330.

2. Sastry M, Ahmad A, Khan MI \& Kumar R (2004). Microbial nanoparticle production, in nanobiotechnology, By Niemeyer CM and Mirkin CA. WileyVCH, Weinheim: 126-135.

3. Bhattacharya D \& Rajinder G (2005). Nanotechnology and potential of microorganisms. Cri Rev Biotech 25: 199-204.

4. Mohanpuria P, Rana NK \& Yadav SK (2008). Biosynthesis of nanoparticles: technological concepts and future applications. J NPs Res 10: 507-517.

5. Anselem A (2004). Herbs for healing pax herbals Edo State, Nigeria.

6. Sudhakar M, Rao CV, Rao PM \& Raju DB (2006). Evaluation of antimicrobial activity of Cleome viscosaand Gmelinaasiatica. Fitoterapia 77(1): 47-9.

7. Khan MR, Omoloso AD \& Barewai Y (2006). Antimicrobial activity of the Derris elliptica, Derris indicaand Derris trifoliata extractives. Fitoterapia 77(4): 327-30.

8. Oyetayo VO \& Oyetayo FL (2006). Phytochemical screening and antibacterial properties of siam weed, Chromolaena odorata, leaf against aerobic isolates of wound. J App Env Bio Sci 2(1): 7-11. 
9. Tijani Y, Uguru MO \& Salawu OA (2008). Anti-pyretic, anti-inflamatory and anti-diarrhoel properties of Faidherbia albida in rats. Afr J Biotechn 7(6): 696700.

10. Meruvu S, Hugendubler L \& Mueller E (2011). Regulation of adipocyte differentiation by the zinc finger protein ZNF638. J Bio Chem 286(30): 2651623.

11. Sharma D, Rajput J, Kaith B, Kaur M \& Sharma SS (2010). Synthesis of $\mathrm{ZnO}$ nanoparticles and study of their antibacterial and antifungal properties. Thin Soil Films 519: 1224- 1229.

12. Milind P \& Deep K (2011). Clove: A champion Spice. Int J Res Ayur Pharm 2(1): 47-54.

13. Bhowmik D, Kumar KPS, Yadav A, Srivastava S, Paswan S \& Dutta AS (2012). Recent trends in Indian traditional herbs Syzygium aromaticum and its health benefits. $J$ Pharma Phytochem 1(1): 13-22.

14. Kumar SS, Putcha V, Vanka RR \& Gollapalli NR (2013) Synthesis, characterization and optical properties of zinc oxide nanoparticles. Int Nano Lett 3: 30.

15. Cavassin ED, Luiz FPF, Jose PO, Marcelo MS, Roberto AO, Fabiane F, Valeria SM, Valtencir Z, Anna SSL \& Silvia FC (2015) Comparison of methods to detect the in vitro activity of silver nanoparticles (AgNP) against multidrug resistant bacteria. $J$ Nanobiotech 13: 64.

16. Thunugunta $\mathrm{T}$, Reddy $\mathrm{AC} \&$ Reddy LDC (2015). Green synthesis of nanoparticles: current prospectus. Nanotech Rev 4 (4): 303-323.

17. Ojha AK, Behera S, Rout J, Dash MP \& Nayak PL (2012). Green synthesis of silver nanoparticles from Syzygium aromaticum and their antibacterial efficacy. Int J App Pharma Sci Bio Sci 1(4): 335-341.

18. Pattanayak M, Mohapatra D \& Nayak PL (2013). Green synthesis and characterization of zero valent iron nanoparticles from the leaf extract of Syzygium aromaticum (clove). MiddleEast J Sci Res 18(5): 623-626.

19. Shah RK, Boruah N \& Parween N (2015). Synthesis and characterization of $\mathrm{ZnO}$ nanoparticles using leaf extract of Camellia sinesis and evaluation of their antimicrobial efficacy. Int $J$ Current Micro App Sci 4(8): 444-450.

20. Brayner R, Roselyne F, Nicolas B, Shakib D, Marc FB \& Fernand F (2006). Toxicological Impact Studies Based on Escherichia coli Bacteria in Ultrafine $\mathrm{ZnO}$ Nanoparticles Colloidal Medium. Nano 6(4): 866-870.

21. Roselli M, Finamore A, Garaguso I, Britti MS \& Mengheri E (2003). Zinc oxide protects cultured enterocytes from the damage induced by Escherichia coli. J Nutr 133(12): 4077-82.

22. Berry V, Gole A, Kundu S, Murphy CJ \& Saraf RF (2005). Deposition of CTAB-terminated nanorods on bacteria to form highly conducting hybrid systems. J Am Chem Soc 127: 1760017601. 